\title{
Fascin, a novel marker of human hepatic stellate cells, may regulate their proliferation, migration, and collagen gene expression through the FAK-PI3K-Akt pathway
}

\author{
Naoki Uyama', Yuji limuro' ${ }^{1}$ Norifumi Kawada², Hendrik Reynaert ${ }^{3}, K^{2}$ Kazuhiro Suzumura', Tadamichi Hirano ${ }^{1}$, \\ Nobukazu Kuroda ${ }^{1}$ and Jiro Fujimoto ${ }^{1}$
}

Fascin is a component of actin bundles and may regulate various cellular events. The expression and function of fascin in human hepatic stellate cells (HSCs) has remained largely uncharacterized. Fascin expression in human liver tissue was studied using immunohistochemistry. To identify cells expressing fascin, double immunofluorescent staining with vimentin, $\alpha$-smooth muscle actin $(\alpha$-SMA), or fibulin- 2 was performed and analyzed with confocal microscopy. In culture experiments, fascin expression and the phosphorylation of focal adhesion kinase (FAK) and Akt in LX-2 cells, a cell line of human HSCs, were investigated using western blot. Specific siRNAs were used to reduce the expression of fascin in LX-2 cells. Proliferation and migration were assayed with a CyQuant assay kit and a Matrigel-coated culture insert system, respectively. Levels of matrix metalloproteinase (MMP)-2 and collagen mRNAs were examined using quantitative RT-PCR. Immunohistochemistry revealed the expression of fascin along sinusoids and overlapping with vimentin and $\alpha$-SMA in both non-fibrotic and fibrotic liver tissue, but it was almost absent in periportal myofibroblastic cells and did not colocalize with fibulin-2, a marker of portal myofibroblasts. In addition, fascin immunoreactivity was almost undetectable in septa of fibrotic human liver tissue. The expression of fascin in LX-2 cells was confirmed using western blot. Two different specific siRNAs against fascin significantly reduced the number of viable LX-2 cells to $65 \%$ compared with control cultures and downregulated the mRNAs levels of types I and III collagen and MMP-2 to $62 \%, 65 \%$, and $70 \%$ of control levels, respectively. This condition also reduced the migration activity of LX-2 cells to $46 \%$ of control cells and the phosphorylation level of both FAK and Akt. Fascin may be an excellent novel marker of human HSCs that distinguishes HSCs from periportal myofibroblasts. Fascin may regulate functions of human HSCs through the FAK-phosphoinositide 3-kinase-Akt pathway.

Laboratory Investigation (2012) 92, 57-71; doi:10.1038/labinvest.2011.150; published online 17 October 2011

KEYWORDS: actin-bundling protein; fascin; hepatic stellate cells; liver; portal fibroblasts

Hepatic stellate cells (HSCs) are located in the space of Disse of hepatic sinusoids as liver-specific pericytes interposed by sparse connective tissue and closely adhering to sinusoidal endothelial cells. ${ }^{1}$ They also directly face hepatocytes and, in normal liver, maintain a quiescent phenotype with the main function to store vitamin A. During liver injury, HSCs undergo activation triggered by exposure to cytokines and growth factors, such as platelet-derived growth factor (PDGF) and transforming growth factor- $\beta$, which derive from activated Kupffer cells and damaged hepatocytes. During activation, HSCs transform into a myofibroblast-like phenotype $^{2-4}$ characterized by the expression of $\alpha$-smooth muscle actin $(\alpha$-SMA $),{ }^{5}$ by the production of extracellular matrix (ECM) and matrix degrading enzymes, such as matrix metalloproteinases (MMPs) ${ }^{2-4}$ and tissue inhibitor of metalloproteinases (TIMPs), ${ }^{6,7}$ and by increased proliferation and migration. Activated HSCs are thought to migrate from the sinusoids into necrotic areas and produce a variety of ECM there.

Chronic liver damage leads to fibrotic degeneration of parenchyma, characterized by the formation of fibrotic septa. ${ }^{8}$ Except for HSCs, portal myofibroblasts can produce

\footnotetext{
${ }^{1}$ Department of Surgery, Hyogo College of Medicine, Nishinomiya, Hyogo, Japan; ${ }^{2}$ Department of Hepatology, Graduate School of Medicine, Osaka City University, Osaka, Japan and ${ }^{3}$ Department of Gastroenterology-Hepatology, University Hospital, Vrije Universiteit Brussel (UZ Brussel), Brussels, Belgium Correspondence: Dr N Uyama, MD, PhD, Department of Surgery, Hyogo College of Medicine, Mukogawacho 1-1, Nishinomiya, Hyogo 663-8501, Japan. E-mail: uynk@goo.jp

Received 7 March 2011; revised 21 July 2011; accepted 4 August 2011
} 
collagen in the liver. ${ }^{8}$ Although both cell types show similar expression patterns of intercellular adhesion molecule-1, desmin, vimentin, collagen type IV, fibronectin, and $\alpha$-SMA, several differences between them have also been observed. ${ }^{8}$ For instance, cultured portal myofibroblasts are positive for fibulin-2 and interleukin-6 mRNA, whereas CD95L, $\alpha 2$ macroglobulin, $\mathrm{P} 100$, and reelin are exclusively expressed by activated HSCs. ${ }^{8-14}$ In addition, neural cell adhesion molecule (NCAM), synaptophysin, neurotrophin, neural growth factor, $\alpha \mathrm{B}$-crystallin, and tyrosine kinases are markers that distinguish HSCs from portal myofibroblasts. ${ }^{13,15}$ Experiments using these markers have shown that myofibroblastic cells in fibrotic septa strongly resemble portal myofibroblasts, that they may originate and migrate from the portal tract, and that they are different from sinusoidal HSCs.

Fascin is a member of actin-bundling proteins and causes F-actin to aggregate side-by-side into bundles at filopodia and stress fibers of cultured cells. ${ }^{16,17}$ In humans, the fascin family consists of three isoforms, fascin-1, 2, and 3. Fascin-1, commonly referred to as fascin, is highly expressed in the spleen and brain, moderately in the lungs and placenta, weakly in the skeletal muscle, liver, and tonsil, and undetectably in the heart, kidney, pancreas, and bone marrow. ${ }^{18}$ The expression of fascin-2 and 3 have been reported in the retina and testis, respectively. ${ }^{19,20}$ In addition to neurons, glial cells, and endothelial cells of the brain, ${ }^{16,21-23}$ fascin is expressed in some cancer cells, such as those of the breast, lung, ovary, esophagus, kidney, and colon..$^{20,24-34}$ Cancer cells expressing high levels of fascin exhibit increased membrane protrusions and migration ability, suggesting that fascin is a regulator of cell functions in addition to its cytoskeletal role. As HSCs in the liver with contractile and migratory activity are enriched in actins including $\alpha$-SMA, fascin is also speculated to be present in these cell lineages.

In this study, we demonstrate fascin expression for the first time in non-fibrotic and fibrotic human liver and in a human HSC line, LX-2 cells, and we suggest its candidacy as a novel human HSC marker. Moreover, by reducing fascin expression with siRNA treatment, we also show a role for it in the proliferation, migration, and collagen gene expression of LX-2 cells.

\section{MATERIALS AND METHODS Materials}

The antibodies used in this study are summarized in Table 1. LY294002, a phosphoinositide 3-kinase (PI3K) inhibitor, was obtained from Cell Signaling Technology (Beverly, MA, USA). The Cyquant Cell Proliferation Assay Kit, Lipofectamine siRNAMAX reagent, and Opti-MEM I medium were obtained from Invitrogen (Carlsbad, CA, USA).

Table 1 Primary antibodies used in this study

\begin{tabular}{|c|c|c|c|c|}
\hline \multicolumn{5}{|l|}{ Monoclonal antibodies } \\
\hline Vimentin & Mouse & Vim13.2 & $\lg M$ & Sigma-Aldrich \\
\hline$\beta$-Actin & Mouse & $A C-15$ & $\lg G 1$ & Sigma-Aldrich \\
\hline Heat shock protein 47 & Mouse & M16.10A.1 & $\lg G 2$ & Calbiochem \\
\hline NCAM & Mouse & $1 \mathrm{~B} 6$ & $\lg G 1$ & Leica Novocastra \\
\hline$\alpha-S M A$ & Mouse & $1 \mathrm{~A} 4$ & $\lg G 2 a$ & Thermo Electron \\
\hline CD68 & Mouse & PG-M1 & $\lg G 3$ & DAKO \\
\hline Fibulin-2 & Rabbit & \multicolumn{2}{|c|}{ HPA001934 } & Sigma-Aldrich \\
\hline FAK & Rabbit & \multicolumn{2}{|c|}{ \#3285 } & Cell Signaling Technology \\
\hline Phospho-FAK (Tyr397) & Rabbit & \multicolumn{2}{|c|}{ \#3283 } & Cell Signaling Technology \\
\hline Akt & Rabbit & \multicolumn{2}{|c|}{ \#9272 } & Cell Signaling Technology \\
\hline Phospho-Akt (Ser473) & Rabbit & \multicolumn{2}{|c|}{ \#9271 } & Cell Signaling Technology \\
\hline ERK & Rabbit & \multicolumn{2}{|c|}{ \#9102 } & Cell Signaling Technology \\
\hline Phospho-ERK (Thr202/Tyr204) & Rabbit & \multicolumn{2}{|c|}{ \#9101 } & Cell Signaling Technology \\
\hline
\end{tabular}


Table 2 Clinical information of the patients

\begin{tabular}{|c|c|c|c|c|c|c|c|c|}
\hline Case & Age & Sex & Disease & Virus infection & Alb (g/dl) & Bil (mg/dl) & PT (\%) & Fibrosis score \\
\hline \multicolumn{9}{|c|}{ Non-fibrotic liver } \\
\hline 2 & 61 & $\mathrm{~F}$ & CCA & $\mathrm{HCV}(+)$ & 3.8 & 0.4 & 89.6 & Fo \\
\hline 3 & 66 & M & $\mathrm{HCC}$ & No & 3.8 & 0.8 & 89.4 & F1 \\
\hline 5 & 63 & $\mathrm{~F}$ & CCA & No & 3.7 & 0.6 & 101 & Fo \\
\hline 6 & 36 & $\mathrm{~F}$ & $\mathrm{FNH}$ & No & 4.5 & 0.8 & 87 & Fo \\
\hline \multicolumn{9}{|c|}{ Fibrotic liver } \\
\hline 7 & 63 & M & $\mathrm{HCC}$ & $\mathrm{HCV}(+)$ & 2.9 & 0.7 & 73 & $\mathrm{~F} 4$ \\
\hline
\end{tabular}

Abbreviations: Alb, albumin; Bil, bililubin; CCA, cholangiocarcinoma; F, female; FNH, focal nodular hyperplasia; HBV, hepatitis B virus; HCC, hepatocellular carcinoma; HCV, Hepatitis C virus; M, male; MLC, metastatic liver cancer; PT, prothorombin time.

a This patients administrated warfarin because of cerebral infarction.

\section{Human Liver Tissue}

Human liver tissue specimens were collected during hepatectomies at the Hyogo College of Medicine (Nishinomiya, Hyogo, Japan). Before tissue collection, this study was approved by the Research Ethics Committee of the Hyogo College of Medicine. Informed consent was obtained from all patients. Six non-fibrotic liver tissue samples were taken from non-cancerous regions of liver obtained from patients with cholangiocarcinoma (three), hepatocellular carcinoma (HCC) (one), metastatic liver cancer (one), or focal nodular hyperplasia (FNH) (one). Fibrotic liver tissue was obtained from three patients suffering from chronic viral hepatitis and one patient from primary biliary cirrhosis (PBC) (Table 2).

After hematoxylin and eosin (HE) staining and Sirius Red staining, the liver specimens were examined microscopically. The degree of liver fibrosis was assessed based on the following METAVIR scoring system: ${ }^{35} \mathrm{~F} 0$, no fibrosis; F1, expansion of the portal tracts without linkage; F2, portal expansion with portal to portal linkage; F3, extensive portal to portal and focal portal to central linkage; and F4, cirrhosis.

\section{Immunohistochemistry}

Tissue specimens were fixed for $48 \mathrm{~h}$ in $10 \%$ formalin and embedded in paraffin wax before sectioning. Sections of $4 \mu \mathrm{m}$ thickness for each specimen were prepared on silanized slides (DAKO, Ely, UK). The slides were washed with phosphatebuffered saline (PBS) and then blocked with Protein Block Serum-Free solution (DAKO). Primary antibodies were diluted in PBS, and each antibody solution was added to each slide overnight at $4{ }^{\circ} \mathrm{C}$. The slides were washed three times in PBS for $5 \mathrm{~min}$. Secondary antibody staining was performed using the DAKO EnVision + kit according to the manufacturer's instructions. The slides were then washed three times with $\mathrm{PBS}$ for $5 \mathrm{~min}$, incubated with $3,3^{\prime}$-diaminobenzidine- $\mathrm{H}_{2} \mathrm{O}_{2}$ mixture for another $20 \mathrm{~min}$, rinsed with distilled water, and counterstained with hematoxylin. The sections were dehydrated with an ethanol series followed by xylene and mounted using Malinol (Muto Pure Chemicals, Tokyo, Japan). The staining was visualized under a Nikon Eclipse TS-100 microscope (Nikon, Tokyo, Japan). In addition, to identify colocalization of fascin with vimentin, heat shock protein 47 (HSP47), NCAM, fibulin-2, $\alpha$-SMA, or CD68, human liver tissue samples were labeled with double fluorochrome. Fluorochrome labeling was viewed under a Zeiss Axiovert LSM510 confocal microscope and documented using LSM510 software.

\section{Human HSC Line Culture}

LX-2 cells, a cell line of human HSC, were donated by Dr Scott Friedman (Mount Sinai School of Medicine). ${ }^{36}$ The cells were suspended in RPMI-1640 supplemented with 5\% fetal calf serum, plated on plastic dishes (Iwaki Glass, Chiba, Japan ) and cultured in a humidified atmosphere at $5 \% \mathrm{CO}_{2}$ and $37^{\circ} \mathrm{C}$. Morphology of the cultured cells was observed under a Nikon Eclipse TS-100 microscope (Nikon).

\section{Immunocytochemistry}

Cultured LX-2 cells grown on collagen-coated glass cover slips (Sumitomo Bakelite, Tokyo, Japan) were fixed in cold methanol for $10 \mathrm{~min}$. The cells were permeabilized in $0.1 \%$ Triton X-100 in PBS for 10 min. After washing three times with PBS, the cells were preincubated with $1 \%$ albumin/PBS 
Table 3 Sequence of two siRNAs against fascin

$\begin{array}{ll}\text { siRNA1 } & \\ \begin{array}{l}\text { Sense strand } \\ \text { Antisense strand }\end{array} & 5^{\prime} \text {-AACUCCAGCUGGAAGACGUCAUAGC-3' } \\ \text { siRNA2 } & \\ \text { Sense strand } & 5^{\prime} \text {-UAGAUGGUUGGUCCUUCCAGCUGGAGUU-3' } \\ \text { Antisense strand } & 5^{\prime} \text {-CCAUGCACCCUCAGGUCAACAUCUA-3' }\end{array}$

for $30 \mathrm{~min}$, and then incubated with primary antibody for $1 \mathrm{~h}$ at room temperature. Following washing three times with PBS, the cells were incubated with appropriate fluorochrome-conjugated secondary antibodies for $1 \mathrm{~h}$ at room temperature. The cells were mounted in fluorescent mounting medium (DAKO), observed under a Zeiss Axiovert LSM510 confocal microscope (Carl Zeiss, Jena, Germany) and documented using LSM510 software.

\section{Transfection of siRNA}

LX-2 cells were transfected with siRNA using Lipofectamine RNAiMAX according to the manufacturer's instructions. Two siRNA duplexes for human fascin were synthesized and purified by Invitrogen (Stealth RNAi). The sequences of two siRNA duplexes are summarized in Table 3. Scramble oligo control siRNA duplex was also purchased from Invitrogen, and was used as a control. Two siRNA duplexes for fascin and the scramble oligo control siRNA duplex were dissolved separately in Opti-MEM I. After $10 \mathrm{~min}$ of equilibration at room temperature, each siRNA solution was combined with the respective volume of Lipofectamine solution, mixed gently, and allowed to form siRNA liposomes for $20 \mathrm{~min}$ at room temperature. The transfection mixture was added to antibiotic-free cell culture medium to a final concentration of $50 \mathrm{nM}$. The culture dishes were incubated for $12 \mathrm{~h}$ at $37^{\circ} \mathrm{C}$, at which point the medium was removed and replaced with fresh medium. Assays were performed at 72 and $120 \mathrm{~h}$ after transfection.

\section{RNA Preparation and Quantitative RT-PCR}

Total RNA was extracted from cultured LX-2 cells with TRIZOL Reagent (Invitrogen). Extracted RNA was reversetranscribed using a high-capacity cDNA archive kit (Applied Biosystems, Foster City, CA, USA). Quantitative (q) RT-PCR was performed using the Applied Biosystems 7300 Real-Time PCR System (Applied Biosystems) according to the manufacturer's protocols. Taqman gene expression assays including primers and probes for fascin, MMP-2, TIMP-1, and types I and III collagens were purchased from Applied Biosystems. A predeveloped TaqMan assay reagent for $18 \mathrm{~S}$ ribosomal RNA (18S rRNA) (Applied Biosystems) was used as an internal control. For analysis, according to the Delta-Delta threshold $\left(C_{\mathrm{t}}\right)$ method, ${ }^{37}$ each $C_{\mathrm{t}}$ value was first normalized to the respective $18 \mathrm{~S}$ rRNA $C_{\mathrm{t}}$ value of the sample and afterward to the control. The fold induction was calculated from these $C_{\mathrm{t}}$ values.

\section{Western Blot Analysis}

Cells were homogenized in sample buffer $(62.5 \mathrm{mmol} / \mathrm{l}$ Tris$\mathrm{HCl}, \mathrm{pH} 6.8,2 \%$ sodium dodecyl sulfate (SDS), $1 \mathrm{mM} \mathrm{NaF}$, $1 \mathrm{mM} \mathrm{Na} \mathrm{VO}_{4}$, and $10 \%$ glycerol), and boiled for $10 \mathrm{~min}$. Protein concentrations were determined using the BCA protein assay kit (Pierce, Rockford, IL, USA). Samples were separated by SDS polyacrylamide gel electrophoresis $(5-20 \%$ gradient gel; ATTO, Tokyo, Japan) and electroblotted onto polyvinylidene difluoride membrane (Millipore, Bedford, MA, USA). After blocking with Tris-buffered saline containing $5 \%$ skim milk and $0.1 \%$ Tween 20 at $4{ }^{\circ} \mathrm{C}$ overnight, the membrane was incubated with primary antibodies for $2 \mathrm{~h}$ at $20^{\circ} \mathrm{C}$. After washing, the membrane was then incubated with a secondary antibody for $1 \mathrm{~h}$ at $20^{\circ} \mathrm{C}$. After washing, the antigens were detected with enhanced chemiluminescence using ECL substrate (Amersham, Roosdaal, The Netherlands). Immunoreactive bands were captured using a LAS3000 imaging system (Fujifilm, Tokyo, Japan).

\section{Cell Proliferation Assay}

The CyQUANT Cell Proliferation Assay Kit (Molecular Probes, Eugene, OR, USA) was used in conjunction with a fluorometer (Fluoroskan Ascent, Thermo Fisher Scientific, Waltham, MA, USA) to assess the effect of downregulated fascin expression on the proliferation of LX-2 cells. LX-2 cells (8000 cells) were cultured in 24-well plates (Iwaki Glass) for 5 days after the transfection of siRNAs. At the indicated times, the medium was discarded, and the plates were frozen. For the assay, cells were lysed, and total cellular nucleic acid was measured using florescence at $520 \mathrm{~nm}$ emission after excitation at $480 \mathrm{~nm}$.

\section{Phosphorylation Assay}

At $72 \mathrm{~h}$ after the transfection of siRNA against fascin, the culture medium was exchanged with serum-free RPMI-1640 and cells were cultured for $3 \mathrm{~h}$. Then, culture medium was changed to RPMI-1640 supplemented with $10 \%$ FCS, and the culture was incubated for another $60 \mathrm{~min}$. the phosphorylation of focal adhesion kinase (FAK), Akt, and extracellular signal-regulated kinase (Erk) was investigated using western blot.

\section{Migration Assay}

The migratory capacity of LX-2 cells was investigated with a BIOCOAT MATRIGEL Invasion Chamber (Becton Dickinson) placed in the well of a 24 -well tissue culture plate (Becton Dickinson). In these experiments, $1 \mathrm{ml}$ of RPMI$1640 / 5 \%$ FBS was added to the lower chamber of the well, and LX-2 cells transfected with siRNA against fascin for 3 days $(1200$ cells) were suspended in $0.5 \mathrm{ml}$ of RPMI$1640 / 5 \%$ FBS and added to the upper chamber. After $24 \mathrm{~h}$ of 
incubation, the medium in the upper chamber was changed to FBS-free RPMI-1640 medium and that of the lower chamber was changed to RPMI-1640/10\% FBS. After $24 \mathrm{~h}$ of additional incubation, the culture medium was removed, and cells adhering to the membrane were fixed with $10 \%$ formalin and stained with Giemsa solution. The number of LX-2 cells on the lower surface was counted in four microscopic fields randomly chosen for each specimen using a Nikon Eclipse TS-100 microscope.

\section{Statistical Analysis}

The data are expressed as the mean \pm s.d. All experiments using cells were repeated at least three independent times. The statistical significance of the differences between two sample groups was calculated with the Mann-Whitney test. Differences were considered significant at $P<0.05$.

\section{RESULTS}

Expression of Fascin in Human Non-Fibrotic Liver Tissue To detect fascin in human liver tissue samples, immunohistochemical analysis was performed. Six liver specimens were obtained from three patients with cholangiocarcinoma, one with FNH, one with HCC, and one with metastatic liver cancer (Table 2, cases 1-6). These specimens were stained with HE (Supplementary Figures 1a, d, g, j, m, and p) and Sirius Red (Supplementary Figures $1 \mathrm{~b}, \mathrm{e}, \mathrm{h}, \mathrm{k}, \mathrm{n}$, and $\mathrm{q}$ ). In cases 1,3, and 4, expansion of the portal tracts without linkage was found (Supplementary Figures $1 \mathrm{a}, \mathrm{b}, \mathrm{g}, \mathrm{h}, \mathrm{j}$, and $\mathrm{k}$ ), and in the other cases, no fibrosis was found (Supplementary Figures $1 \mathrm{~d}, \mathrm{e}, \mathrm{m}, \mathrm{n}, \mathrm{p}$, and $\mathrm{q}$ ). In addition, we performed immunohistochemistry for $\alpha$-SMA in all six cases. $\alpha$-SMA immunoreactivity was found in periportal areas, but this immunoreactivity was scarcely found in intralobular areas. According to the METAVIR scoring system, these specimens were diagnosed as F0 (cases 2, 5, and 6) or F1 (cases 1, 3, and 4).

Immunohistochemistry for fascin (Supplementary Figures $2 \mathrm{a}-\mathrm{c}$ and $\mathrm{g}-\mathrm{i}$ ) and vimentin (Supplementary Figures $2 \mathrm{~d}-\mathrm{f}$ and $\mathrm{j}-\mathrm{l})$, which is a marker of mesenchymal cells, was performed in serial sections to determine the locations of HSCs and portal myofibroblastic cells in the liver, and the results for cases $2(\mathrm{a}-\mathrm{f})$ and cases $4(\mathrm{~g}-\mathrm{l})$ are shown in Supplementary Figure 2. Fascin immunoreactivity was found in intralobular areas of all six non-fibrotic liver tissue samples, and fascin-positive perisinusoidal cells appeared identical to vimentin-positive cells. Notably, in the periportal area of all six non-fibrotic liver tissue samples, the portal myofibroblastic cells were vimentin positive, but fascin negative. To confirm that the fascin-positive cells in the intralobular area are identical to HSCs, double immunofluorescent staining for fascin plus either vimentin, HSP47 or NCAM, which are markers of HSCs, was performed (Supplementary Figure 2, case 2). Confocal microscopy confirmed that fascin immunoreactivity clearly overlapped with that of vimentin and the other two HSC marker proteins. In contrast, the expression of $\alpha$-SMA, a marker of periportal myofibroblasts and activated HSCs, and fibulin-2, a marker of periportal myofibroblasts, but not HSCs, were undetectable in the parenchyma of non-fibrotic liver tissues. In periportal areas, $\alpha$-SMA and fibulin-2 immunoreactivity were detectable, but they were not colocalized with that of fascin. Taken together, these data indicate that HSCs, but not periportal myofibroblastic cells, express fascin.

\section{Expression of Fascin in Human Fibrotic Liver Tissue}

Four liver specimens were obtained from three patients with viral hepatitis and one patient with PBC (Table 2, cases 7-10). These specimens were stained with HE (Supplementary Figures 4a, d, g, and j) and Sirius Red (Supplementary Figures $1 \mathrm{~b}, \mathrm{e}, \mathrm{h}$, and $\mathrm{k}$ ). In all cases, portal-portal linkage and/or portal-central linkage were found (Supplementary Figures la, b, d, e, g, h, j, and k). We also performed immunohistochemistry for $\alpha$-SMA. In all cases, $\alpha$-SMA immunoreactive cells were found in sinusoid areas as well as periportal areas. According to the METAVIR scoring system, all these specimens were diagnosed as F4.

Immunohistochemistry for fascin (Figures $1 \mathrm{a}-\mathrm{c}$ and $\mathrm{g}-\mathrm{i}$ ) and vimentin (Figures $1 \mathrm{~d}-\mathrm{f}$ and $\mathrm{j}-\mathrm{l}$ ) in fibrotic liver tissues were performed and the results for cases $7(a-f)$ and cases 10 (g-l) are shown in Figure 1. Similarly to non-fibrotic liver, many star-shaped perisinusoidal cells were fascin positive (Figures 1a, b, g, and h) and vimentin positive (Figures 1d, e, $\mathrm{j}$, and $\mathrm{k}$ ) in all four fibrotic liver tissue samples. On the other hand, myofibroblastic cells localized in periportal areas and fibrotic septa were fascin negative (Figures $\mathrm{lb}, \mathrm{c}, \mathrm{h}$, and i), but vimentin positive (Figures le, f, k, and l). To confirm the findings mentioned above, we performed double immunofluorescent staining for fascin plus either vimentin, HSP47, NCAM, fibulin-2, or $\alpha$-SMA (Figure 2, case 7). Similarly to non-fibrotic liver, fascin immunoreactivity was present and overlapped with that of vimentin (Figure 2), HSP47 (Figure 2), NCAM (Figure 2), and $\alpha$-SMA (Figures 2 and 3) in intralobular areas. In fibrotic septa, immunoreactivity was strongly positive for vimentin (Figure 2), fibulin-2 (Figure 2), and $\alpha$-SMA (Figure 2), but was undetectable for fascin. To check whether other sinusoidal cells express fascin, we performed double immunofluorescent staining for fascin plus CD68, a marker of Kupffer cells (Figure 3). We found that some fascin immunoreactive cells were CD68 positive.

Taken together, these data indicate that fascin is expressed by HSCs in intralobular sinusoids, but not by myofibroblastic cells in the periportal area or fibrotic septa. In addition, myofibroblastic cells in fibrotic septa resemble periportal fibroblasts rather than HSCs. In addition to HSCs, Kupffer cells may express fascin.

\section{Comparison of Fascin Expression Between Non-Fibrotic Liver and Fibrotic Liver}

To investigate whether fascin expression is upregulated during HSC activation, we compared fascin expression between 

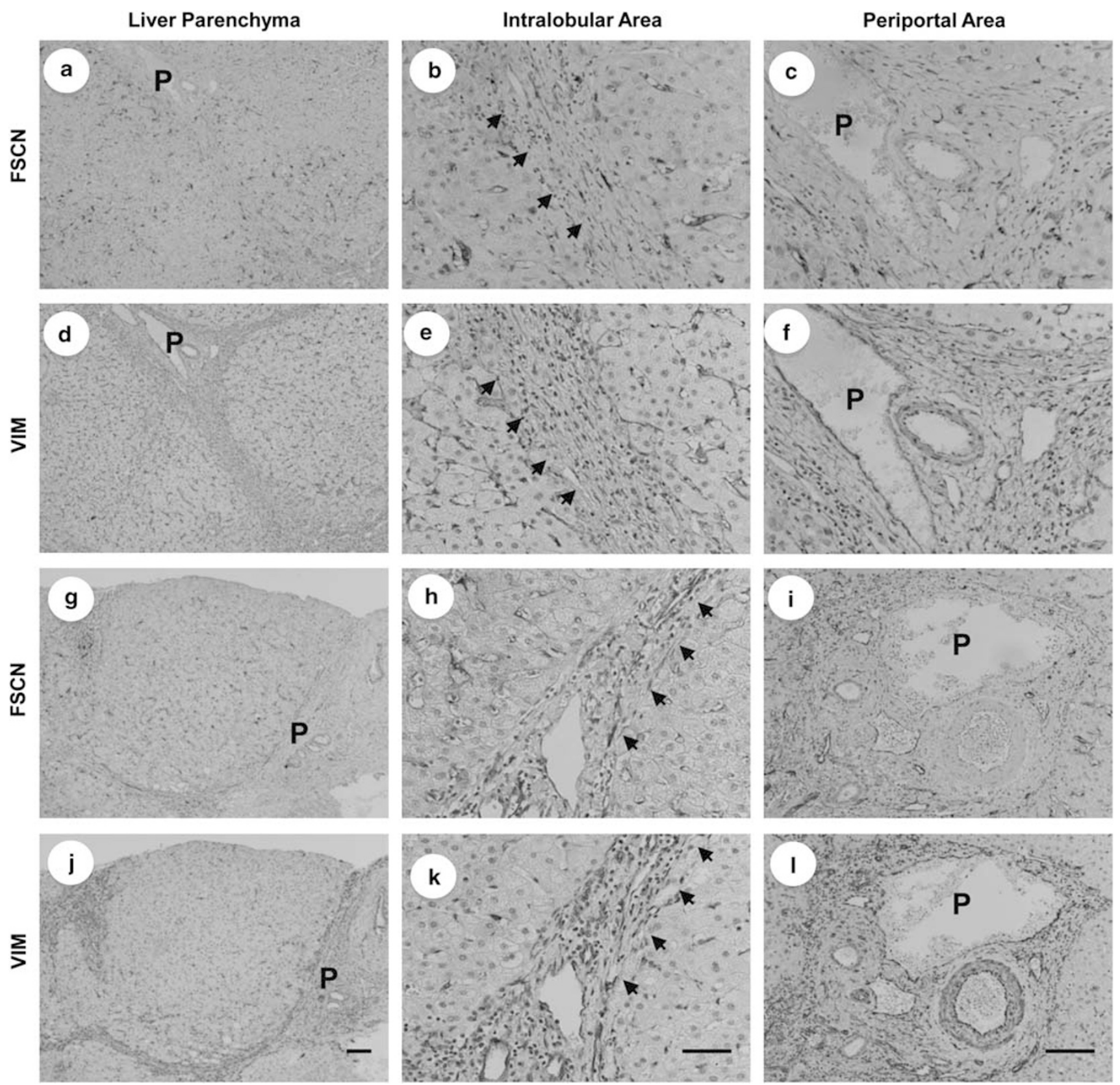

Figure 1 Expression of fascin in human fibrotic liver. Fibrotic liver specimens were obtained from patients with hepatitis viral (a-f: case 7 in Table 2) and primary biliary cirrhosis (g-l: case 10 in Table 2). Immunohistochemistry for fascin (a-c and $\mathbf{g}-\mathbf{i}$ ) and vimentin (d-f and $\mathbf{j}-\mathbf{l})$ was performed on serial sections; $\mathbf{a}$ and $\mathbf{d}, \mathbf{b}$ and $\mathbf{e}, \mathbf{c}$ and $\mathbf{f}, \mathbf{g}$ and $\mathbf{j}, \mathbf{h}$ and $\mathbf{k}$, and $\mathbf{i}$ and $\mathbf{I}$, respectively, are serial sections. Both fascin $(\mathbf{a}, \mathbf{b}, \mathbf{g}$, and $\mathbf{h})$ and vimentin $(\mathbf{d}, \mathbf{e}, \mathbf{j}$, and $\mathbf{k})$ immunoreactivity was found at perisinusoidal cells in intralobular areas of the liver. In the fibrotic septa (b, e, $\mathbf{h}$, and $\mathbf{k}$ ) and periportal area

(c, $\mathbf{f}, \mathbf{i}$, and $\mathbf{I}$ ), myofibroblastic cells were vimentin positive, but fascin negative. Arrows indicate the portion of fibrotic septum. Magnification is $\times 100$ for $\mathbf{a}, \mathbf{d}, \mathbf{g}$, and $\mathbf{j}$, and the bar indicates $100 \mu \mathrm{m}$. Magnification is $\times 400$ for others and the bar indicates $50 \mu \mathrm{m}$. Abbreviations: FSCN, fascin; $P$, portal vein area; VIM, vimentin.

non-fibrotic and fibrotic liver tissue. In non-fibrotic liver tissue, although sinusoidal HSCs did not express $\alpha$-SMA at all (Figures 4a-c, case 6), many fascin immunoreactive cells were found in sinusoidal areas (Figures $4 \mathrm{~d}-\mathrm{f}$, case 6 ). Judging from the shapes of the fascin-positive cells, $\alpha$-SMA-negative HSCs were expressing fascin. In fibrotic liver, sinusoidal HSCs expressed $\alpha$-SMA (Figures $4 \mathrm{~g}-\mathrm{i}$, case 8 ) and many fascin immunoreactive cells were found in sinusoidal areas (Figures 4j-l, case 8). Judging from the shapes of the fascinpositive cells, $\alpha$-SMA-positive HSCs were expressing fascin. These results indicate that fascin may be expressed by quiescent and activated HSCs, and a significant difference in fascin expression was not found between non-fibrotic and fibrotic liver tissue. 


\section{Fascin Colocalizes with $\beta$-Actin Filaments and Vinculin in LX-2 Cells}

To confirm fascin expression in human HSCs, immunocytochemistry was performed in cultured LX-2 cells (Figure 5). LX-2 cells were reported to express $\alpha$-SMA, vimentin, and glial fibrillary acidic protein and to have the ability to store retinol and retinyl esters, indicating their close relationship to HSCs. ${ }^{36}$ Fascin was found to be ubiquitously present in the cytoplasm of LX-2 cells and to form fiber-like structures. Next, we investigated the colocalization of fascin with $\beta$-actin, $\alpha$-SMA, and vinculin because fascin has been reported to function as a component of cytoplasmic microfilamentous bundles that contribute to cell architecture and intracellular movements and to be a component of cortical
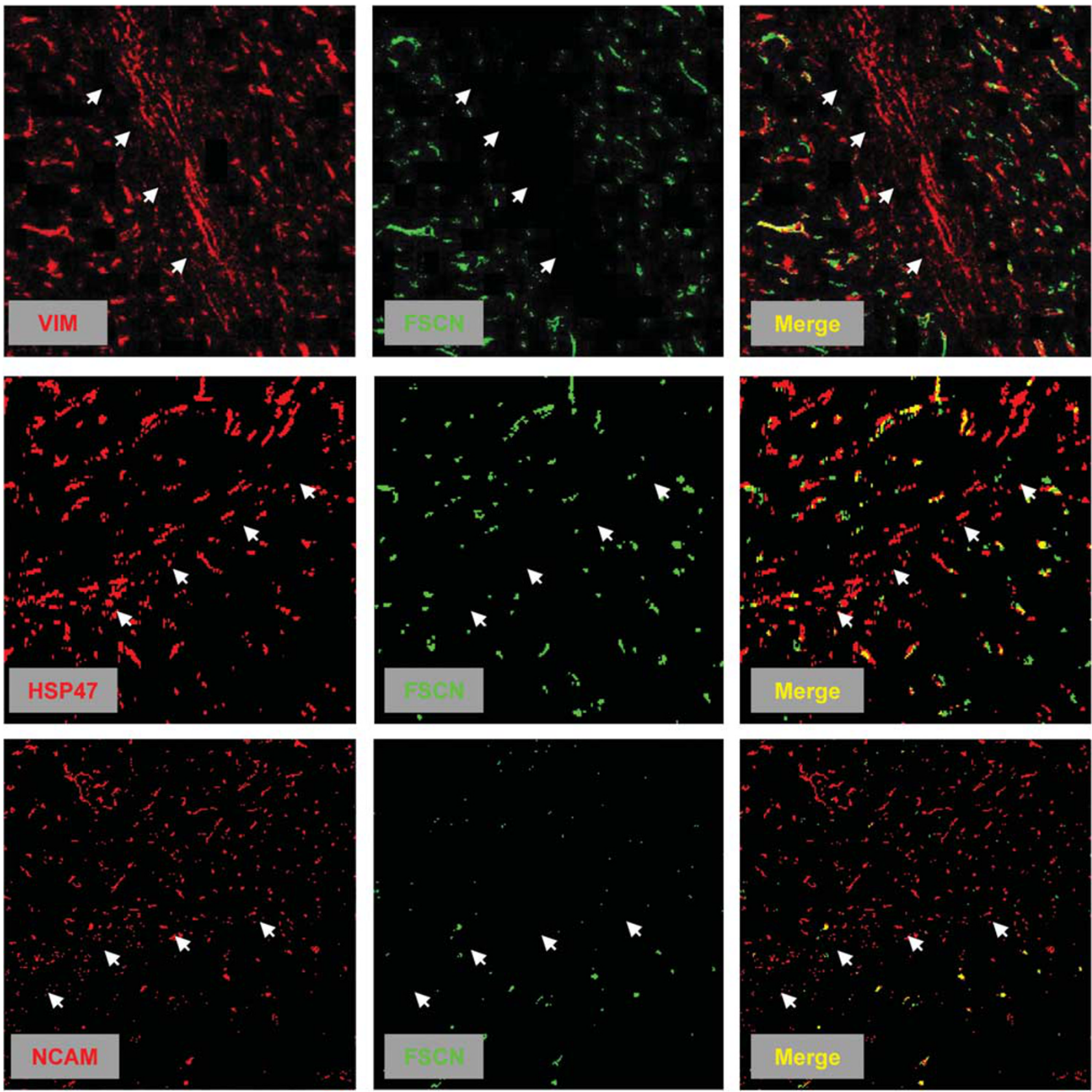

Figure 2 Immunofluorescent staining for fascin, vimentin, HSP47, NCAM, fibulin-2, and $\alpha$-SMA in human fibrotic liver tissue. Double immunofluorescent staining for fascin (FSCN) plus vimentin (VIM), HSP47, NCAM, fibulin-2 (FIB2), or $\alpha$-SMA was performed (case 5 in Table 2) and analyzed with confocal microscopy. Vimentin, HSP47, NCAM, fibulin-2, and $\alpha$-SMA were labeled with Alaxa 488 (red) and fascin was with Alaxa 546 (green). In intralobular areas, fascin immunoreactivity overlapped with that of vimentin, HSP47, NCAM, and $\alpha$-SMA. In fibrotic septa, fascin immunoreactivity was almost undetectable and did not overlap with that of vimentin, HSP47, NCAM, or $\alpha$-SMA. Arrows indicate the portion of fibrotic septum. Original magnification is $\times 200$ and the bar indicates $100 \mu \mathrm{m}$. 

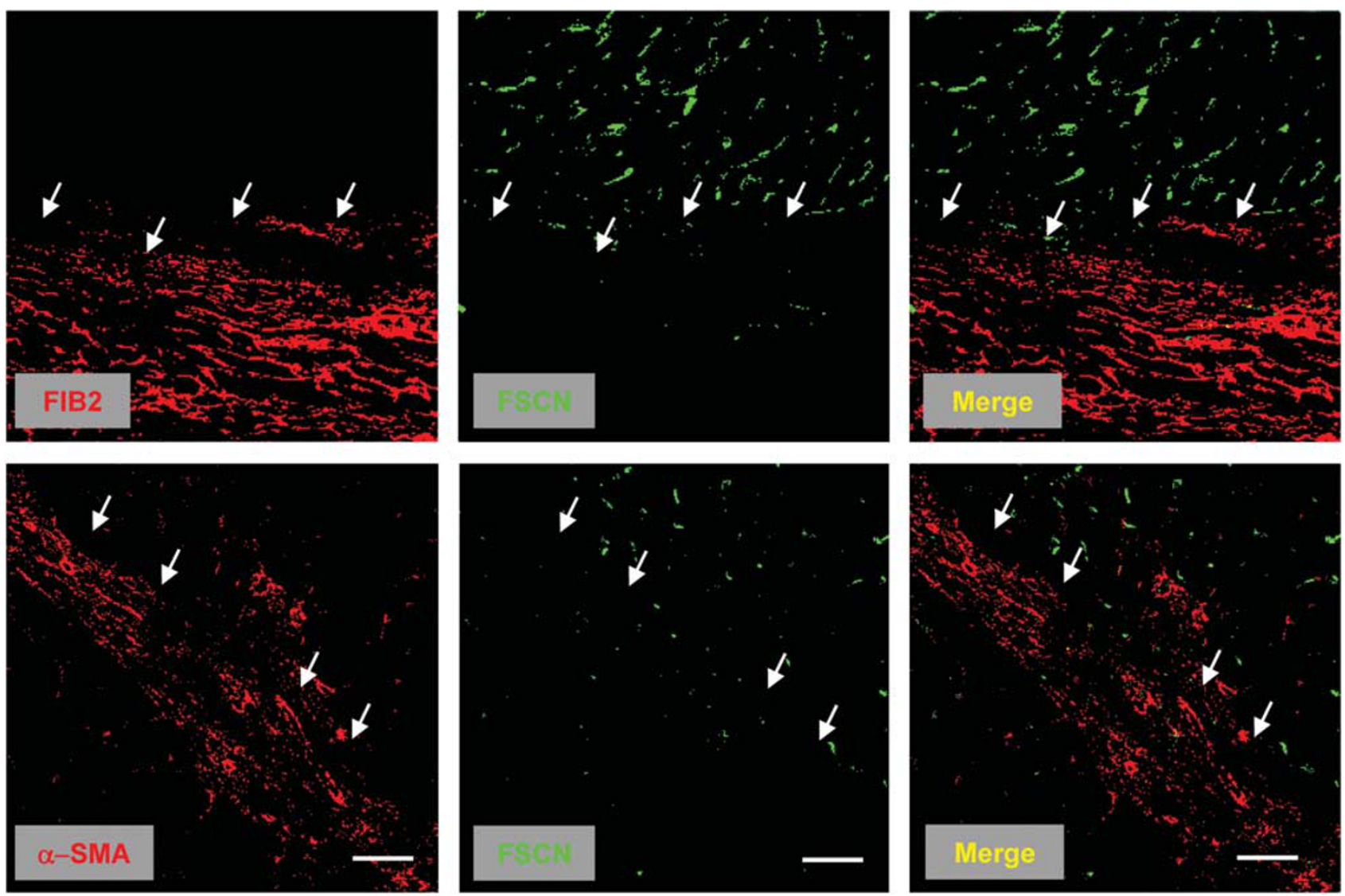

Figure 2 Continued.

cell protrusions that mediate cell interactions with ECM and migration. Double immunofluorescent staining showed that fascin colocalized with $\beta$-actin and $\alpha$-SMA and formed stress fibers (Figure 5). It also colocalized with vinculin at focal adhesions of the LX-2 cells (Figure 5, white arrow). These data indicate that fascin may be involved in the regulation of the actin-based structure of LX-2 cells and may interact with focal adhesions.

\section{Reducing Fascin Expression Compromises the Survival of LX-2 Cells}

Next, we aimed to clarify the role of fascin expression in HSCs. For this purpose, we reduced the level of fascin in LX-2 cells. Scrambled siRNA (as a negative control) and two specific siRNAs targeting fascin (siRNA1 and 2) were transfected into LX-2 cells. qRT-PCR revealed that the expression of fascin mRNA in LX-2 cells transfected with either siRNA1 or 2 was downregulated to $24.9 \pm 0.5 \%$ or $20.3 \pm 3.0 \%$ of control cells, respectively (Figure 6a). Similarly, fascin protein levels were also reduced without affecting the level of vimentin, as shown using western blot (Figure 6b). At $72 \mathrm{~h}$ after transfection, phase contrast microscopic observation of cell shape showed that cell body extension was inhibited in LX-2 cells treated with siRNA1 or 2 compared with that of control cells (Figure 6c). Evaluation of the number of viable cells using a CyQuant assay kit indicated that at $72 \mathrm{~h}$, the fascin-depleted cell/control cell ratio was $65.2 \pm 8.7 \%$ and $71.8 \pm 1.8 \%$, respectively, for siRNA1- or 2-transfected cells, and at $120 \mathrm{~h}$, it was $68.4 \pm 8.0 \%$ and $82.6 \pm 11.6 \%$, respectively (Figure 6d).

\section{Downregulation of Akt Activation by Fascin Depletion}

To clarify the mechanisms by which fascin depletion reduces cell survival, we investigated the phosphorylation of FAK, Akt, and Erk. Mechanistic analyses indicated that, compared with the control conditions, fascin reduction by siRNA decreased the serum-induced phosphorylation of FAK and Akt (Figure 7a), but it had a negligible effect on the phosphorylation of ERK (Figure 7a). In addition, $10 \mu \mathrm{M}$ LY294002, a PI3K inhibitor, significantly decreased LX-2 cell survival to $70.0 \pm 5.8 \%$ of control cells (Figure $7 \mathrm{~b}$ ) in a manner similar to the effect of the siRNAs against fascin. These data indicate that fascin may regulate cell survival through the FAK-PI3K-Akt pathway.

\section{Downregulation of Collagen Gene Expression by Fascin Depletion}

To study the role of fascin in functions of LX-2 cells other than cell survival, the effect of fascin depletion on the expression of collagen types I and III genes was evaluated 



Figure 3 Colocalization of fascin with $\alpha$-SMA or CD68 in human fibrotic liver tissue. Double immunofluorescent staining for fascin (FSCN) plus $\alpha$-SMA or CD68 was performed (case 8 in Table 2) and analyzed with confocal microscopy. $\alpha$-SMA and CD68 were labeled with Alaxa 488 (red) and fascin was with Alaxa 546 (green). In intralobular areas, fascin immunoreactivity overlapped with that of $\alpha$-SMA (white arrows) and partially overlapping with that of CD68 (white arrow heads). Original magnification is $\times 400$ and the bar indicates $100 \mu \mathrm{m}$.

using qRT-PCR. At $72 \mathrm{~h}$ after transfection, siRNA1 and 2 significantly reduced the expression of type I collagen to $76.3 \pm 13.0 \%$ and $66.8 \pm 13.7 \%$ of the control, respectively (Figure $8 \mathrm{a}$ ). Similarly, siRNA1 and 2 significantly reduced the expression of type III collagen to $73.7 \pm 2.8 \%$ and $62.5 \pm 8.3 \%$ (Figure $8 \mathrm{~b}$ ) of the control, respectively. In addition, LY294002 $(10 \mu \mathrm{M})$ significantly decreased the expression of types I and III collagen to $43.1 \pm 3.0 \%$ (Figure $8 \mathrm{c}$ ) and $37.8 \pm 2.5 \%$ (Figure $8 \mathrm{~d}$ ) of the control, respectively, in a manner similar to the effects of the siRNAs. These data indicate that fascin may regulate the expression of types I and III collagen through the FAK-PI3K-Akt pathway.

\section{Inhibition of Migration and MMP-2 Gene Expression by Fascin Depletion}

The effects of fascin depletion and LY294002 on the migration of LX-2 cells were further evaluated using a Matrigelcoated culture insert invasion assay. The number of cells on the lower membrane was significantly reduced to $49.9 \%$ and $46.2 \%$ of the control, respectively, in siRNA1- or 2-transfected cells (Figure 9a). LY294002 $(10 \mu \mathrm{M})$ also significantly reduced the migration ability of LX-2 cells to $50.3 \%$ of the control (Figure 9b). Next, we investigated the effect of fascin depletion and LY294002 on MMP-2 and TIMP-1 mRNA levels in LX-2 cells using qRT-PCR. At $72 \mathrm{~h}$ after transfection, siRNA1 and 2 significantly reduced the expression of MMP-2 to $74.1 \pm 5.5 \%$ and $69.7 \pm 7.1 \%$ of the control, respectively (Figure 9c). Similarly, LY294002 $(10 \mu \mathrm{M})$ significantly reduced the expression of MMP-2 to $49.9 \pm 8.6 \%$ of the control (Figure 9d). On the other hand, neither fascin depletion (Figure 9e) nor LY294002 (10 $\mu \mathrm{M})$ (Figure 9f) had a noticeable effect on the expression of TIMP-1 mRNA.

\section{Discussion}

Fascin is principally expressed in neural and mesenchymal derivatives during embryogenesis. ${ }^{38}$ In adult organs, fascin is strongly expressed in tissues such as brain and spleen, and its expression is thought to be highly tissue- and cell type-specific. $^{16,21-23}$ As fascin expression in the liver is low, detailed analysis of fascin expression in the human liver has not yet been conducted. In this study, we found that fascin is present in intralobular sinusoidal areas, but not in the periportal areas or fibrotic septa of the human liver. In addition, the localization of fascin in the sinusoidal area is similar to that 

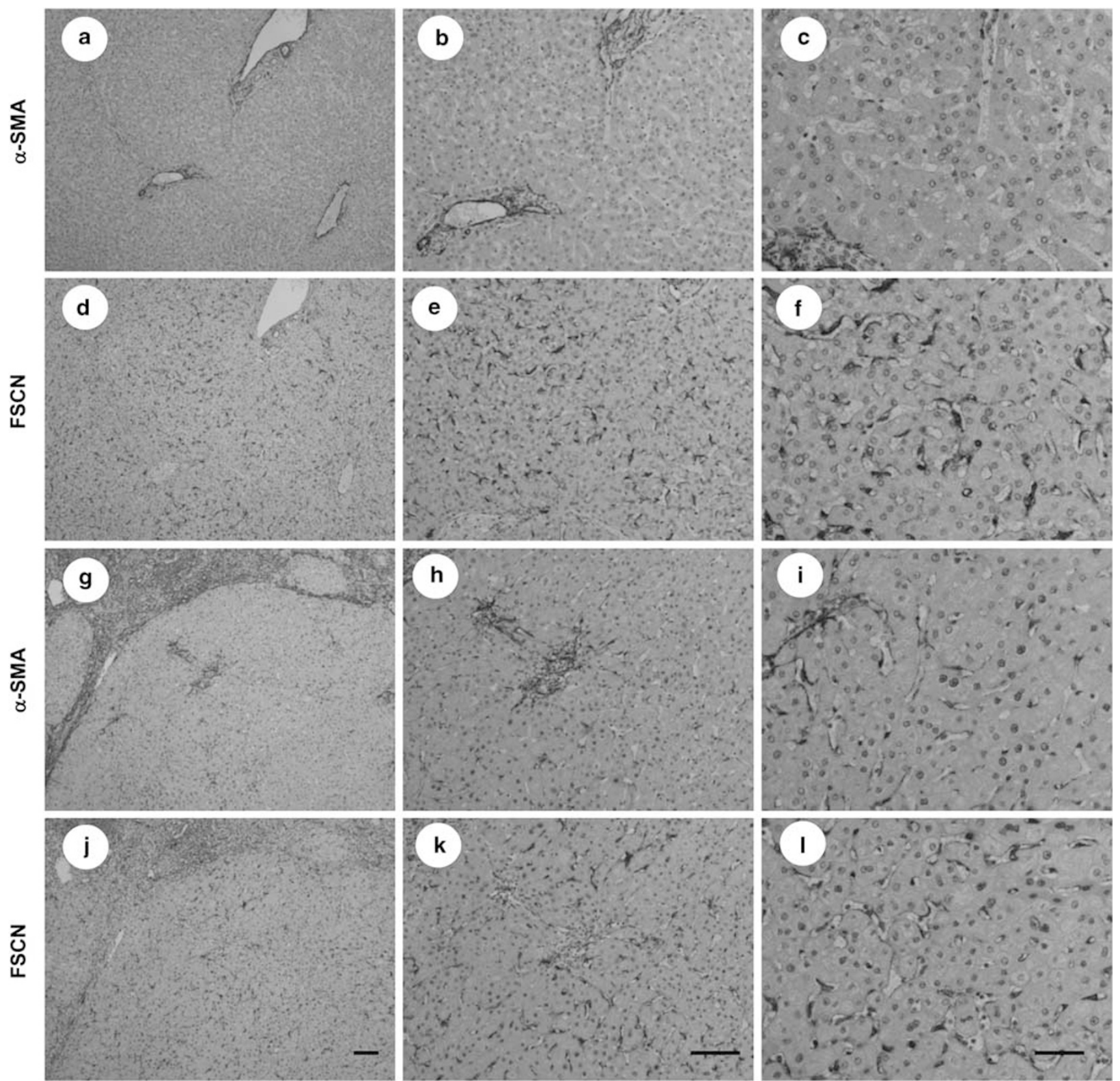

Figure 4 Comparison of fascin expression between human non-fibrotic liver and fibrotic liver tissue. Immunohistochemistry for $\alpha$-SMA (a-c, $\mathbf{g}-\mathbf{i})$ and fascin (d-f, $\mathbf{j}-\mathbf{l}$ ) was performed on serial sections; $\mathbf{a}-\mathbf{c}$ and $\mathbf{d}-\mathbf{f}$, and $\mathbf{g}-\mathbf{i}$ and $\mathbf{j}-\mathbf{I}$ are serial sections, respectively. The results for non-fibrotic liver specimens (a-f: case 6 in Table 2) and fibrotic liver specimens (g-l: case 8 in Table 2) were shown. In case 6, there were many star-shaped fascin-positive cells in the sinusoidal areas (d-f), although there were no $\alpha$-SMA-positive cells (a-c). In case 8 , there were many $\alpha$-SMA-positive cells ( $\mathbf{g}$-i) and many fascin-positive cells (j-l) in the sinusoidal areas. Magnification is $\times 100$ for $\mathbf{a}, \mathbf{d}, \mathbf{g}$ and $\mathbf{j}$ and the bar indicates $100 \mu \mathrm{m}$. Magnification is $\times 200$ for $\mathbf{b}$, e, $\mathbf{h}$, and $\mathbf{k}$ and the bar indicates $100 \mu \mathrm{m}$. Magnification is $\times 400$ for $\mathbf{c}, \mathbf{f}, \mathbf{i}$, and $\mathbf{I}$ and the bar indicates $50 \mu \mathrm{m}$. FSCN, fascin.

of vimentin. Thus, we speculate that fascin-positive cells are human HSCs. It has been reported that vimentin, HSP47 and $\alpha$-SMA are expressed by both HSCs and portal myofibroblasts, ${ }^{39,40}$ that NCAM is expressed by human HSCs and nervous cells in the periportal area, ${ }^{15,41}$ and that fibulin-2 is expressed by periportal myofibroblasts, but not by HSCs. ${ }^{11}$ The present analyses showed that cells expressing fascin overlap with those expressing vimentin, HSP47, and NCAM in intralobular areas of the liver (Figure 2 and Supplementary Figure 3). In addition, in intralobular areas of fibrotic liver tissue, cells expressing fascin overlap with those expressing $\alpha$-SMA (Figure 3). On the other hand, in periportal areas of non-fibrotic liver tissue and fibrotic septa of fibrotic liver tissue, fascin immunoreactivity is almost negative and does not overlap with that of vimentin, HSP47, fibulin-2, or $\alpha$-SMA (Figure 2 and Supplementary Figure 3). According to 

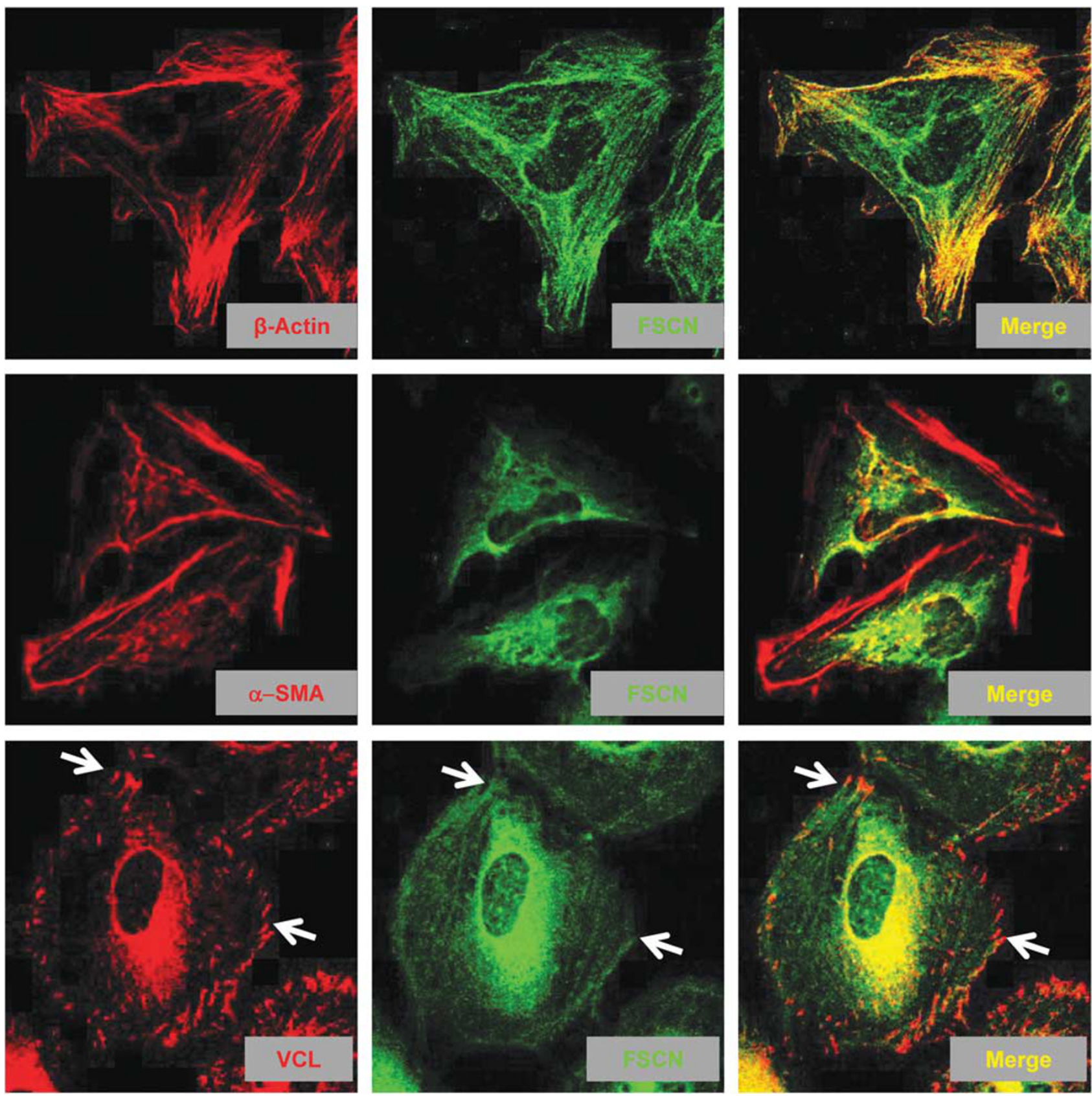

Figure 5 Immunofluorescent staining for fascin, $\beta$-actin, $\alpha$-SMA, and vinculin in LX-2 cells. Double immunofluorescent staining for fascin (FSCN) plus $\beta$-actin, $\alpha$-SMA or vinculin in LX-2 cells was performed and analyzed with confocal microscopy. $\beta$-actin, $\alpha$-SMA, and vinculin were labeled with Alaxa 488 (red) and fascin was with Alaxa 546 (green). $\beta$-Actin (red) and fascin (green) immunoreactivity showed fibrous staining and clearly overlapped (Merge). $\alpha$-SMA (red) and fascin (green) immunoreactivity showed fibrous staining and partially overlapped (Merge). Immunoreactivity for fascin (green) and vinculin (VCL, red) also overlapped at the periphery of LX-2 cells (arrows in Merge). Original magnification is $\times 800$.

these observations, we conclude that fascin is localized in human HSCs, but not in (myo)fibroblasts of the periportal area or fibrotic septa. To clarify, which cell type other than HSCs express fascin, we performed double immunofluorescent staining for fascin plus CD68 (Figure 3). This experiment showed that some fascin-positive cells express CD68, indicating that Kupffer cells may express fascin.
Recently, Hayashi et al ${ }^{42}$ demonstrated that fascin is expressed in sinusoidal endothelial cells in rat liver, but not in mouse liver. In this study, because we could not perform sufficient quality of CD34 immunostaining, we cannot comment on fascin expression in sinusoidal endothelial cells at the present time. Although fascin expression in human sinusoidal endothelial cells remains to be studied, the prominent 
a

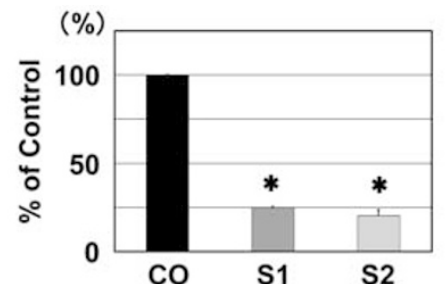

b

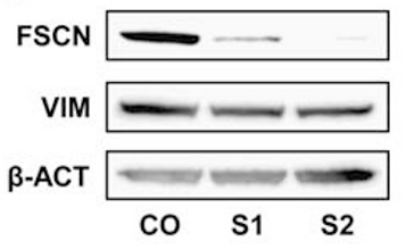

c

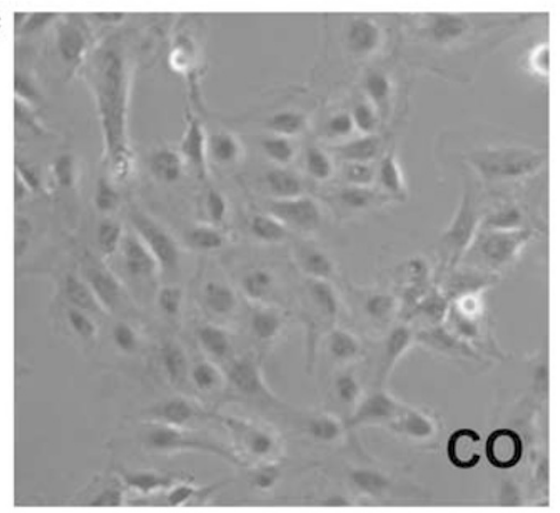

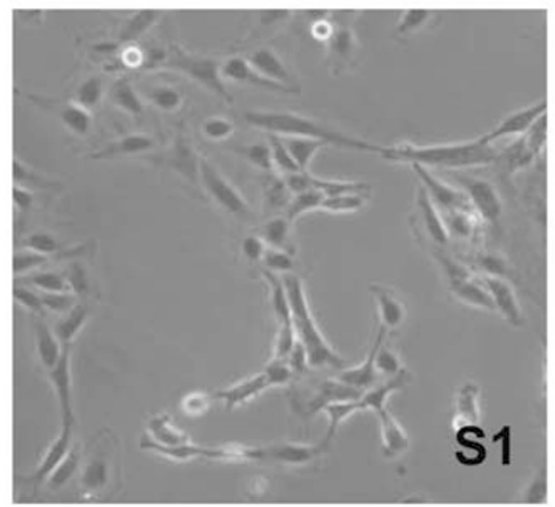
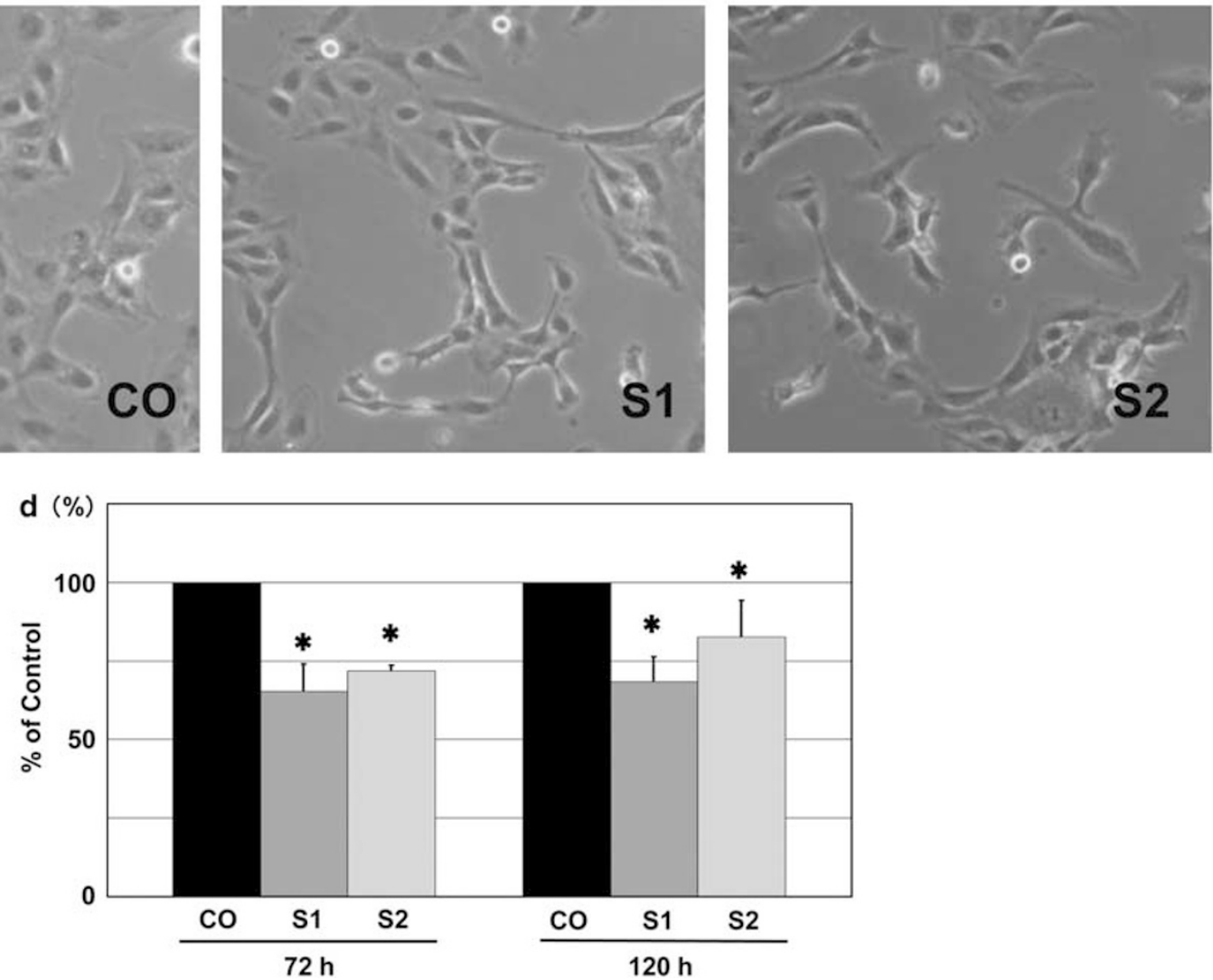

Figure 6 Transfection of siRNAs against fascin into LX-2 cells. (a) Fascin mRNA expression in LX-2 cells. Quantitative RT-PCR indicates that fascin expression in LX-2 cells was significantly downregulated by transfection of siRNAs (S1 or S2). CO, non-targeting siRNAs. Results are depicted as percentage of the control. Values of the means \pm s.d. of three independent experiments are indicated. ${ }^{*} P<0.05$. (b) Fascin protein expression in LX-2 cells. At western blot analysis, fascin expression in LX-2 cells was significantly down regulated by transfection of siRNAs (S1 or S2). CO, non-targeting siRNAs. (c) Morphology of LX-2 cells. Morphology was observed under a phase contrast microscope. Fascin depletion led morphological change of LX-2 cells at $72 \mathrm{~h}$ after transfection. Original magnification is $\times 400$. (d) Survival of LX-2 cells. At 72 and $120 \mathrm{~h}$ after transfection of siRNAs (S1 and S2) against fascin or non-targeting siRNAs (CO) into LX-2 cells, viable cells were evaluated by the CyQuant assay kit. Results are depicted as percentage of the control and values of the means \pm s.d. of three independent experiments are indicated. ${ }^{*} P<0.05$.

expression of fascin in cultured LX-2 cells and its colocalization with vimentin, HSP47, NCAM, and $\alpha$-SMA in human liver tissue confirms the presence of fascin in HSCs.

As in vitro experiments indicated that fascin might be involved in regulating the proliferation and migration of LX-2 cells, we assumed that there would be a marked difference in fascin expression between non-fibrotic and fibrotic liver tissues. However, unexpectedly, fascin expression was observed along sinusoids in the intralobular area of both fibrotic and non-fibrotic liver tissue samples (Figure 4). This indicates that fascin is a constitutive component of HSCs that acts similarly to $\beta$-actin, maintaining an even level independently of the status of HSC activation. It can also be concluded that HSCs remain relatively activated in the intralobular areas of intact human liver and fibrotic liver because fascin-positive cells express NCAM, the expression of which increases during HSC activation. ${ }^{41}$

There are reports describing the involvement of fascin in cell morphology, proliferation, and movement. Jawhari et $a l^{26}$ reported that fascin overexpression in human colon adenocarcinoma cells increases dynamic cell protrusions. It has also been reported that fascin is associated with the proliferation of human colon adenocarcinoma cells, non-small cell lung adenocarcinoma, and esophageal squamous cell 
a

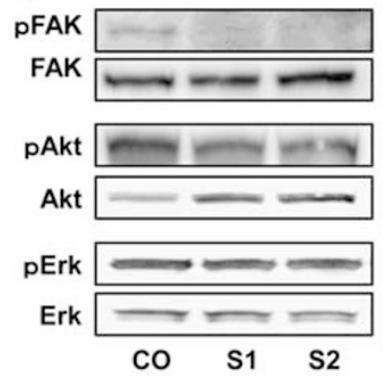

b

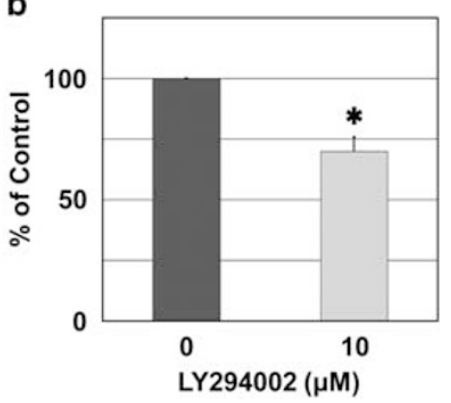

Figure 7 Effect of fascin depletion on the activation of FAK-associated signaling of $L X-2$ cells. (a) Effect of fascin depletion on the activation of FAK, Akt, and ERK. At $72 \mathrm{~h}$ after transfection of siRNAs (S1 and S2) against fascin or non-targeting siRNAs (CO) into LX-2 cells, the culture medium was exchanged with serum-free RPMI- 1640 and cells were cultured for $3 \mathrm{~h}$. Then, culture medium was changed to RPMI-1640 supplemented with 10\% FCS, and the culture was incubated for another $60 \mathrm{~min}$ the phosphorylation of FAK, Akt, and extracellular signal-regulated kinase (Erk) was investigated using western blot. (b) Effect of LY294002 on the number of viable LX-2 cells. At $48 \mathrm{~h}$ after adding $10 \mu \mathrm{M}$ LY294002, a PI3K inhibitor, to LX-2 cell culture, the number of viable cells were evaluated by the CyQuant assay kit. Results are depicted as percentage of the control. Values of the means \pm s.d. of three independent experiments are indicated. ${ }^{*} P<0.05$.
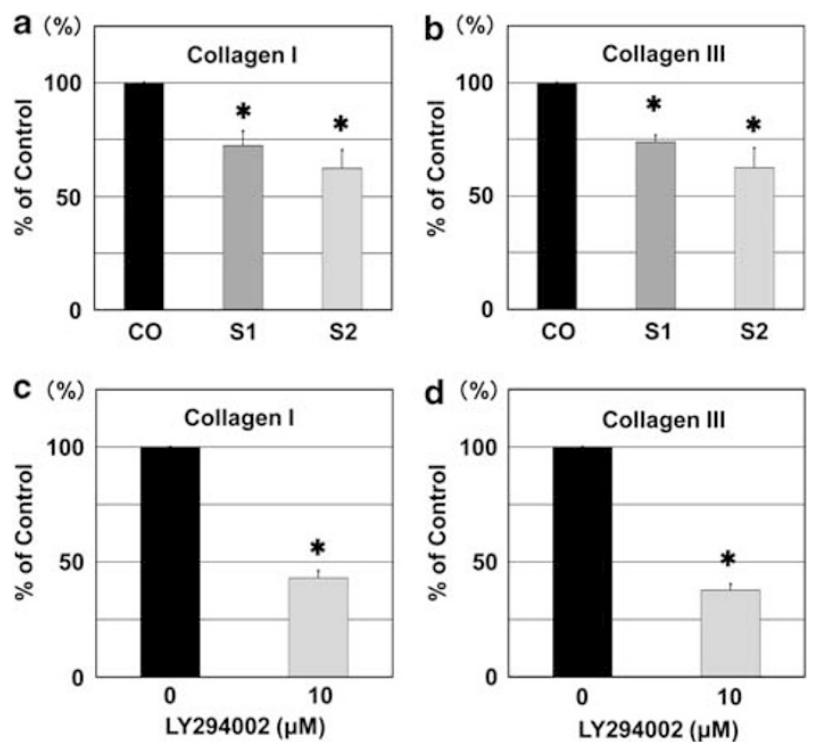

Figure 8 Effect of fascin depletion and LY294002 on collagen gene expression in LX-2 cells. (a, b) Gene expression of types I and III collagen by LX-2 cells transfected with siRNAs (S1 and S2) against fascin or nontargeting siRNAs (CO) for $72 \mathrm{~h}$ was evaluated by qRT-PCR. (c, d) Gene expression of types I and III collagen by LX-2 cells treated with $10 \mu \mathrm{M}$ LY294002 for $48 \mathrm{~h}$ was evaluated by qRT-PCR. Results are depicted as percentage of the control. Values of the means \pm s.d. of three independent experiments are indicated. ${ }^{\star} P<0.05$.

carcinoma ${ }^{26,27,30,34}$ and with motility and invasiveness of colon adenocarcinoma cells and esophageal carcinoma cells. ${ }^{26,30,34}$ Similarly, we observed in this study that fascin in LX-2 cells may be involved in cell morphology, proliferation, and migration.
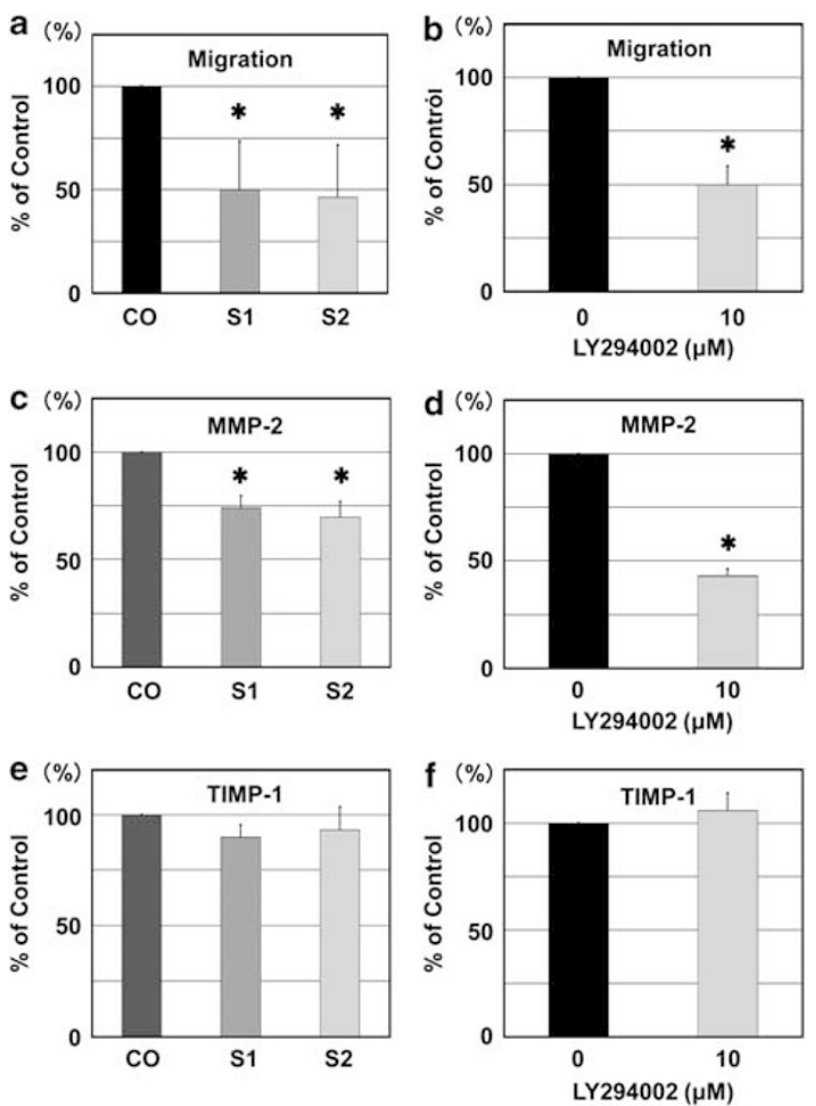

Figure 9 Effect of fascin depletion and LY294002 on the migration ability and expression of MMP-2 and TIMP- 1 of LX- 2 cells. $(\mathbf{a}, \mathbf{b})$ The migration ability of LX-2 cells transfected with two kinds of siRNAs (S1 and S2) against fascin or non-targeting siRNAs (CO) for $72 \mathrm{~h}$ (a) or treated with $10 \mu \mathrm{M}$ LY294002 (b) for $48 \mathrm{~h}$. The number of cells migrating from the upper membrane to the lower membrane was counted. Results are depicted as percentage of the control and values of the means \pm s.d. of three independent experiments are indicated. ${ }^{*} P<0.05$. (c, e) Gene expression of MMP-2 (c) and TIMP-1 (e) was assayed by qRT-PCR in LX-2 cells transfected with two kinds of siRNAs (S1 and S2) against fascin or non-targeting siRNAs (CO) for $72 \mathrm{~h}$. Results are depicted as percentage of the control and values of the means \pm s.d. of three independent experiments are indicated. ${ }^{*} P<0.05$. (d, f) Gene expression of MMP-2 (d) and TIMP-1 (f) was assayed by qRT-PCR in LX-2 cells treated with $10 \mu \mathrm{M}$ LY294002 for $48 \mathrm{~h}$. Results are depicted as percentage of the control and values of the means \pm s.d. of three independent experiments are indicated. ${ }^{*} P<0.05$.

The carboxyl-terminal tyrosine residue of FAK constitutes a major phosphorylation site, appears to be important for the tyrosine phosphorylation of proteins associated with focal complexes, and it creates a high-affinity binding site recognized by the SH-2 domain of the Src family. The recruitment and activation of Src through the formation of a bipartite kinase complex results in the activation of the Ras-Raf-ERK pathway. ${ }^{43,44}$ In addition, Akt is serine-phosphorylated following the tyrosine phosphorylation of FAK. ${ }^{43}$ Recently, it was reported that fascin overexpression leads to increased focal contact formation by human colon adenocarcinoma cells. ${ }^{26}$ Therefore, we speculate that focal 
adhesions may be involved in the mechanisms whereby fascin regulates the behavior of LX-2 cells. In fact, we found that fascin colocalizes with $\beta$-actin and vinculin in LX-2 cells (Figure 4). We also found that fascin depletion suppresses the serum-induced phosphorylation of FAK and Akt, but not ERK (Figure 7). Thus, fascin may regulate cell behavior through the FAK-PI3K-Akt pathway rather than the FAKRas-Raf-Erk pathway in LX-2 cells. Moreover, Reif et al ${ }^{45}$ reported that adenovirus-mediated transfection of a dominant-negative form of FAK into HSCs inhibits the phosphorylation of FAK and blocks both PDGF-induced migration and type I collagen gene expression through the PI3K-Akt pathway. Bae et $a l^{46}$ reported that MMP-2 expression is regulated through the PI3K-Akt pathway in gastric cancer cells. In this study, we found that in LX-2 cells, fascin depletion and LY294002 treatment both significantly reduce cell migration and the gene expression of types I and III collagen and MMP-2, but not that of TIMP-1 (Figures 8 and 9).

In summary, fascin is present in HSCs of both non-fibrotic and fibrotic human liver tissue, and it is absent in periportal myofibroblasts as well as in myofibroblastic cells in fibrotic septa. Fascin may be functionally involved in extension, survival, migration, and the expression of MMP-2 and collagen genes in HSCs through the FAK-PI3K-Akt pathway.

Supplementary Information accompanies the paper on the Laboratory Investigation website (http://www.laboratoryinvestigation.org)

\section{ACKNOWLEDGEMENTS}

We thank Ms K Aizawa for technical help of biological experiments and $\mathrm{K}$ Mitani for skillful assistance of immunohistochemistry. This study was supported by JSPS Grant-in-Aid for Scientific Research (C) (KAKENHI 18591513), (KAKENHI 23592001), and JSPS Grant-in-Aid for Scientific Research (B) (KAKENHI 19390342).

\section{DISCLOSURE/CONFLICT OF INTEREST}

The authors declare no conflict of interest.

1. Wake K. Perisinusoidal stellate cells (fat-storing cells, interstitial cells, lipocytes), their related structure in and around the liver sinusoids, and vitamin A-storing cells in extrahepatic organs. Int Rev Cytol 1980;66:303-353.

2. Friedman SL. Seminars in medicine of the Beth Israel Hospital, Boston. The cellular basis of hepatic fibrosis. Mechanisms and treatment strategies. N Engl J Med 1993;328:1828-1835.

3. Pinzani M. Novel insights into the biology and physiology of the Ito cell. Pharmacol Ther 1995;66:387-412.

4. Gressner AM. Cytokines and cellular crosstalk involved in the activation of fat-storing cells. J Hepatol 1995;22:28-36.

5. Ramadori G, Veit T, Schwogler S, et al. Expression of the gene of the alpha-smooth muscle-actin isoform in rat liver and in rat fat-storing (ITO) cells. Virchows Archiv 1990;59:349-357.

6. Iredale JP, Benyon $\mathrm{RC}$, Arthur $\mathrm{MJ}$, et al. Tissue inhibitor of metalloproteinase-1 messenger RNA expression is enhanced relative to interstitial collagenase messenger RNA in experimental liver injury and fibrosis. Hepatology (Baltimore, MD) 1996;24:176-184.

7. Theret N, Musso $O$, L'helgoualc'h $A$, et al. Activation of matrix metalloproteinase- 2 from hepatic stellate cells requires interactions with hepatocytes. Am J Pathol 1997;150:51-58.

8. Ramadori G, Saile B. Portal tract fibrogenesis in the liver. Lab Invest J Tech Methods Pathol 2004;84:153-159.
9. Dubuisson L, Lepreux S, Bioulac-Sage $P$, et al. Expression and cellular localization of fibulin-1 in normal and pathological human liver. J Hepatol 2001;34:514-522.

10. Saile B, Matthes N, Neubauer K, et al. Rat liver myofibroblasts and hepatic stellate cells differ in CD95-mediated apoptosis and response to TNF-alpha. Am J Physiol 2002;283:G435-G444.

11. Knittel T, Kobold D, Saile B, et al. Rat liver myofibroblasts and hepatic stellate cells: different cell populations of the fibroblast lineage with fibrogenic potential. Gastroenterology 1999;117:1205-1221.

12. Kobold D, Grundmann A, Piscaglia F, et al. Expression of reelin in hepatic stellate cells and during hepatic tissue repair: a novel marker for the differentiation of HSC from other liver myofibroblasts. J Hepatol 2002;36:607-613.

13. Cassiman D, Libbrecht L, Desmet V, et al. Hepatic stellate cell/ myofibroblast subpopulations in fibrotic human and rat livers. J Hepatol 2002;36:200-209.

14. Dranoff JA, Kruglov EA, Robson SC, et al. The ecto-nucleoside triphosphate diphosphohydrolase NTPDase2/CD39L1 is expressed in a novel functional compartment within the liver. Hepatology (Baltimore, MD) 2002;36:1135-1144.

15. Nakatani K, Seki S, Kawada N, et al. Expression of neural cell adhesion molecule (N-CAM) in perisinusoidal stellate cells of the human liver. Cell Tissue Res 1996;283:159-165.

16. Adams JC. Formation of stable microspikes containing actin and the $55 \mathrm{kDa}$ actin bundling protein, fascin, is a consequence of cell adhesion to thrombospondin-1: implications for the anti-adhesive activities of thrombospondin-1. J Cell Sci 1995;108(Part 5):1977-1990.

17. Yamashiro-Matsumura $S$, Matsumura F. Intracellular localization of the 55-kD actin-bundling protein in cultured cells: spatial relationships with actin, alpha-actinin, tropomyosin, and fimbrin. J Cell Biol 1986;103:631-640.

18. Mosialos G, Yamashiro S, Baughman RW, et al. Epstein-Barr virus infection induces expression in B lymphocytes of a novel gene encoding an evolutionarily conserved 55-kilodalton actin-bundling protein. J Virol 1994;68:7320-7328.

19. Adams JC. Roles of fascin in cell adhesion and motility. Curr Opin Cell Biol 2004;16:590-596.

20. Hashimoto Y, Skacel M, Adams JC. Roles of fascin in human carcinoma motility and signaling: prospects for a novel biomarker? Int J Biochem Cell Biol 2005;37:1787-1804.

21. Edwards RA, Bryan J. Fascins, a family of actin bundling proteins. Cell Motility Cytoskeleton 1995;32:1-9.

22. Adams JC. Characterization of cell-matrix adhesion requirements for the formation of fascin microspikes. Mol Biol Cell 1997;8:2345-2363.

23. Adams JC, Kureishy N, Taylor AL. A role for syndecan-1 in coupling fascin spike formation by thrombospondin-1. J Cell Biol 2001;152: 1169-1182.

24. Grothey A, Hashizume R, Ji H, et al. C-erbB-2/HER-2 upregulates fascin, an actin-bundling protein associated with cell motility, in human breast cancer cell lines. Oncogene 2000;19:4864-4875.

25. Grothey A, Hashizume R, Sahin AA, et al. Fascin, an actin-bundling protein associated with cell motility, is upregulated in hormone receptor negative breast cancer. Br J Cancer 2000;83:870-873.

26. Jawhari AU, Buda A, Jenkins M, et al. Fascin, an actin-bundling protein, modulates colonic epithelial cell invasiveness and differentiation in vitro. Am J Pathol 2003;162:69-80.

27. Pelosi G, Pasini F, Sonzogni A, et al. Prognostic implications of neuroendocrine differentiation and hormone production in patients with stage I nonsmall cell lung carcinoma. Cancer 2003;97: 2487-2497.

28. Hashimoto $Y$, Skacel $M$, Lavery IC, et al. Prognostic significance of fascin expression in advanced colorectal cancer: an immunohistochemical study of colorectal adenomas and adenocarcinomas. BMC Cancer 2006;6:241.

29. Kabukcuoglu S, Ozalp SS, Oner U, et al. Actin bundling protein fascin expression in ovarian neoplasms: comparison of histopathologic features of tumors obtained by the first and secondary cytoreduction surgeries. Eur J Gynaecol Oncol 2006;27:123-128.

30. Zhang $H, X u L, X i a o ~ D$, et al. Fascin is a potential biomarker for earlystage oesophageal squamous cell carcinoma. J Clin Pathol 2006;59:958-964.

31. Zigeuner R, Droschl N, Tauber V, et al. Biologic significance of fascin expression in clear cell renal cell carcinoma: systematic analysis of 
primary and metastatic tumor tissues using a tissue microarray technique. Urology 2006;68:518-522.

32. Puppa G, Maisonneuve $P$, Sonzogni $A$, et al. Independent prognostic value of fascin immunoreactivity in stage III-IV colonic adenocarcinoma. Br J Cancer 2007;96:1118-1126.

33. Vignjevic D, Kojima $S$, Aratyn $Y$, et al. Role of fascin in filopodial protrusion. J Cell Biol 2006;174:863-875.

34. Xie JJ, Xu LY, Zhang HH, et al. Role of fascin in the proliferation and invasiveness of esophageal carcinoma cells. Biochem Biophys Res Commun 2005;337:355-362.

35. Bedossa P, Poynard T. An algorithm for the grading of activity in chronic hepatitis C. The MRTAVIR Cooperative Study Group. Hepatology (Baltimore, MD) 1996;24:289-293.

36. $\mathrm{Xu} \mathrm{L}$, Hui $\mathrm{AY}$, Albanis $\mathrm{E}$, et al. Human hepatic stellate cell lines, LX-1 and LX-2: new tools for analysis of hepatic fibrosis. Gut 2005;54: 142-151.

37. PE Applied Biosystems. Relative quantitation of gene expression. ABI Prism 7700 sequence detection system: User Bulletin \#2, 1997 pp 11-15.

38. De Arcangelis A, Georges-Labouesse E, Adams JC. Expression of fascin-1, the gene encoding the actin-bundling protein fascin-1, during mouse embryogenesis. Gene Expr Patterns 2004;4:637-643.
39. Herbst $H$, Frey $A$, Heinrichs $O$, et al. Heterogeneity of liver cells expressing procollagen types I and IV in vivo. Histochem Cell Biol 1997;107:399-409.

40. Kawada N, Kuroki T, Kobayashi K, et al. Expression of heat-shock protein 47 in mouse liver. Cell Tissue Res 1996;284:341-346.

41. Knittel T, Aurisch S, Neubauer K, et al. Cell-type-specific expression of neural cell adhesion molecule (N-CAM) in Ito cells of rat liver. Upregulation during in vitro activation and in hepatic tissue repair. Am J Pathol 1996;149:449-462.

42. Hayashi Y, Toda K, Saibara T, et al. Expression of fascin-1, an actinbundling protein, in migrating hepatoblasts during rat liver development. Cell Tissue Res 2008;334:219-226.

43. Giancotti FG, Ruoslahti E. Integrin signaling. Science (New York, NY) 1999;285:1028-1032.

44. Parsons CJ, Takashima M, Rippe RA. Molecular mechanisms of hepatic fibrogenesis. J Gastroenterol Hepatol 2007;22(Suppl 1):S79-S84.

45. Reif S, Lang A, Lindquist JN, et al. The role of focal adhesion kinasephosphatidylinositol 3-kinase-akt signaling in hepatic stellate cell proliferation and type I collagen expression. J Biolog Chem 2003;278: 8083-8090.

46. Bae IH, Yoon $\mathrm{SH}$, Lee SB, et al. Signaling components involved in Bcl-winduced migration of gastric cancer cells. Cancer Lett 2009;277:22-28. 